\title{
Semaphorin signaling in angiogenesis, lymphangiogenesis and cancer
}

\author{
Atsuko Sakurai ${ }^{1}$, Colleen Doci ${ }^{1}, \mathrm{~J}$ Silvio Gutkind ${ }^{1}$ \\ ${ }^{I}$ Oral and Pharyngeal Cancer Branch, National Institute of Dental and Craniofacial Research, National Institutes of Health, 30 \\ Convent Drive, Rm. 211, Bethesda, MD 20892, USA \\ Cell Research (2012) 22:441. doi:10.1038/cr.2012.21; published online 2 February 2012
}

Correction to: Cell Research (2012) 22:23-32. doi:10.1038/cr.2011.198; published online 13 December 2011

The authors apologized for the mis-spelling of the second author's name and the delay notice. The correct form is as follows.

Atsuko Sakurai, Colleen L Doçi, J Silvio Gutkind 